\title{
Asymmetric Effects of Decontamination Using Topical Antibiotics for the ICU Patient
}

\author{
James C. Hurley ${ }^{+}(\mathbb{C}$
}

Citation: Hurley, J.C. Asymmetric Effects of Decontamination Using Topical Antibiotics for the ICU Patient. Symmetry 2021, 13, 1027. https://doi.org/10.3390/sym13061027

Academic Editors: Delia Muntean,

Miroslav Miletín, Corina Musuroi and Iulia-Cristina Bagiu

Received: 19 May 2021

Accepted: 4 June 2021

Published: 8 June 2021

Publisher's Note: MDPI stays neutral with regard to jurisdictional claims in published maps and institutional affiliations.

Copyright: (C) 2021 by the author. Licensee MDPI, Basel, Switzerland. This article is an open access article distributed under the terms and conditions of the Creative Commons Attribution (CC BY) license (https:/ / creativecommons.org/licenses/by/ $4.0 /)$.
Department of Rural Health, Melbourne Medical School, University of Melbourne, Ballarat 3350, Australia; jamesh@bhs.org.au

+ Current address: Internal Medicine Service, Ballarat Health Services, P.O. Box 577, Ballarat 3353, Australia.

\begin{abstract}
There are several antiseptic, antibiotic and non-decontamination-based interventions for preventing intensive care unit (ICU) acquired infection. These have been evaluated in $>200$ studies. Infection prevention using topical antibiotic prophylaxis (TAP) appears to be the most effective. Whether antibiotic use in the ICU may influence the risk of infection among concurrent control patients within the same ICU and result in asymmetrical herd effects cannot be resolved with individual studies examined in isolation. The collective observations within control and intervention groups from numerous ICU infection prevention studies simulates a multi-center natural experiment enabling the herd effects of antibiotics to be evaluated. Among the TAP control groups, the incidences for both ventilator associated pneumonia (VAP) and mortality are unusually high in comparison to literature-derived benchmarks. Paradoxically, amongst the TAP intervention groups, the incidences of mortality are also unusually high and the VAP incidences are similar (i.e., not lower) compared to the incidences among studies of other interventions. By contrast, the mortality incidences among the intervention groups of other studies are similar to those among the intervention groups of TAP studies. Using topical antibiotics to prevent infections acquired within the ICU environment may result in profoundly asymmetrical effects.
\end{abstract}

Keywords: bacteremia; topical antibiotic prophylaxis; study design; intensive care; mechanical ventilation; selective digestive decontamination; herd effects; ventilator associated pneumonia

\section{Introduction}

Patients in the ICU are at high risk of acquiring a range of infections during their ICU stay [1]. For patients staying more than $48 \mathrm{~h}$, the risks of ventilator-associated pneumonia (VAP) [2], bacteremia [3] and candidemia [4] are as high as $25 \%, 10 \%$ and $1 \%$, respectively. Multiple factors, such as the presence of invasive devices such as central lines or endotracheal intubation increase the risk. Infections acquired during the patient's ICU stay complicate their management and increase the mortality risk. The ICU mortality is generally $22.7 \%$ in this patient group with similar incidences among control and intervention groups of 145 studies $(37,156$ patients) of infection prevention interventions whether using antibiotic or non-antibiotic methods [5]. Moreover, there are major challenges in the diagnosis, treatment and prevention of each of these infections.

ICU-acquired infections generally originate from bacteria and candida colonizing the patient's microbiome. This colonizing flora originates from external sources, including the ICU environment itself, and by transmission from the microbiomes of other patients concurrent within the ICU. Antibiotic use, while it might prevent infections in individual patients, will contribute to the disruption of the microbiome within ICU patients and the ICU environment itself. Is it possible that using antibiotics to prevent the development of an infection in individuals might asymmetrically compound or even increase the risk of infection for other patients in the ICU context [6]? 
The goal here is to test the presumption of symmetry between the effect of antibiotic prophylaxis at the level of individual patients versus the effect of the same antibiotic prophylaxis at the level of the population among studies as reported in the literature.

\section{Prevention Interventions}

The origin of most ICU-acquired infections from the patient's colonizing microbiome underlies various ICU infection prevention strategies [7-29]. These can be broadly classified as interventions based on decontamination using topical antibiotic prophylaxis (TAP) [7-14], decontamination using topical antiseptics, such as chlorhexidine [15-17] and non-decontamination-based intervention strategies [18-27]. Examples of non-decontamination strategies might be different methods of airway management [14-24] or different methods of preventing stress ulceration, which through effects on stomach acid secretion, influence stomach colonization secondarily $[25,26]$. Even different methods of enteral feeding may influence the infection risk through the influence on stomach colonization [27].

These preventative interventions broadly target key colonization sites such as the oropharynx, the gastrointestinal tract or the skin, depending on the specific ICU-acquired infection of interest. The interventions are variously applied as mouth washes (the oropharynx), as enteral applications (the gastrointestinal tract) or as body washes (targeting the skin). By contrast, the effect of TAP is believed to be mediated through the control of gut overgrowth with bacteria [28,29].

Further complicating this topic, the studies of these various infection prevention interventions have evaluated different endpoints: pneumonia, bacteremia and candidemia. For example, even the mortality census may have been ICU, hospital or 28-day mortality, or other timepoints [30]. To further complicate the evaluation of these studies of prevention strategies, three main study design types have been used. For some studies, this was the typical randomized control trial (RCT) study design, comparing the incidences of endpoints among concurrent patients individually randomized to receive intervention versus standard care within the same ICU. For other studies, the control group comprised non-concurrent patients from historical periods of standard care. In yet other instances, the study protocol dictated that the control group patients receive protocolized parenteral antibiotic prophylaxis (duplex studies). The third type is a cluster randomized trial (CRT) design, wherein each ICU are randomly assigned to deliver either only intervention or only standard care to each eligible patient. This last type of study design reflects the philosophy that were a successful prevention strategy to be found, it would be applied to all eligible patients as part of an ICU bundle of care rather than patients selectively. This type of study design also ensures that the intervention should not influence the outcome of control patients through effects on the ICU microbiome as the intervention and control patients are non-concurrent.

\section{Is There an Effective Prevention Method?}

There are over 200 studies of these various antibiotic and non-antibiotic-based methods of ICU infection prevention strategies conducted over the past 40 years and many, but not all, have been included within systematic reviews of the specific interventions. Summarizing the collective results is not simple given the range of interventions, the lack of uniformity within each intervention category, the different study endpoints and the various study designs used.

Despite this heterogeneity, overall, the most effective method appears to be that based on oropharyngeal applications of TAP, with (selective digestive decontamination; SDD) or without (selective oropharyngeal decontamination; SOD) the additional use of protocolized parenteral antibiotic prophylaxis [31]. The use of TAP applied with or without additional protocolized parenteral antibiotic prophylaxis appears to be highly effective, with typical reductions within randomized controlled trials being $\sim 50 \%$ for $\mathrm{VAP}, \sim 20 \%$ for bacteremia and candida infections and $15 \%$ for overall mortality [31]. Of note, these RCTs typically use control patients who are concurrent and drawn from the same ICU as where the 
intervention patients are located. Moreover, TAP, as variously constituted, is the only method for which a mortality reduction has been claimed within systematic reviews of the various VAP preventative interventions [7-27,31]. By contrast, non-decontamination-based methods achieve $<50 \%$ reductions in VAP and non-significant effects on mortality. Among studies of antiseptic interventions, oropharyngeal applications of topical chlorhexidine may be associated with reductions in VAP of approximately $25 \%$; however, concern that mortality might be increased by as much as $13 \%$ among recipients of chlorhexidine within studies of non-cardiac ICU patients has led to a reappraisal [16]. The results of 212 VAP prevention studies are summarized in Table 1 . The majority of these studies were selected from systematic reviews that have summarized the effects of each intervention on VAP and mortality incidences.

Table 1. Characteristics of studies ${ }^{1}$.

\begin{tabular}{|c|c|c|c|c|}
\hline Characteristics & Observational & Non-Decontamination & Topical Antiseptic & Topical Antibiotic Studies \\
\hline \multirow{2}{*}{ Number of studies ${ }^{2}$} & & & & \\
\hline & 47 & 81 & 22 & 67 \\
\hline Study publication year (range) & 1986-2019 & 1985-2015 & $2000-2018$ & 1973-2018 \\
\hline \multirow{2}{*}{$\begin{array}{l}\text { Numbers of patients per } \\
\text { study group (median) }\end{array}$} & & & & \\
\hline & 278 & 63 & 65 & 80 \\
\hline$(\mathrm{IQR})^{3}$ & $175-487$ & $44-100$ & $31-114$ & $41-131$ \\
\hline $\begin{array}{l}\text { Mean patient age per } \\
\text { study group (median) }\end{array}$ & 58 & 56 & 55 & 54 \\
\hline$(\mathrm{IQR})^{3}$ & $51-63$ & $49-60$ & $47-58$ & $45-61$ \\
\hline \multirow{3}{*}{$\begin{array}{l}\text { VAP prevention effect } \\
(\text { odds ratio; } 95 \% \mathrm{CI} \mathrm{n})^{4}\end{array}$} & NA & 0.69 & 0.76 & 0.37 \\
\hline & & $0.63-0.76$ & $0.64-0.9$ & $0.34-0.41$ \\
\hline & & 71 & 19 & 62 \\
\hline \multirow{3}{*}{$\begin{array}{l}\text { Mortality prevention effect } \\
(\text { odds ratio; } 95 \% \mathrm{CI} \mathrm{n})^{5}\end{array}$} & NA & 0.69 & 0.76 & 0.37 \\
\hline & & $0.90-1.04$ & $0.95-1.15$ & $0.87-0.96$ \\
\hline & & 86 & 24 & 69 \\
\hline
\end{tabular}

Notes: ${ }^{1}$ The details of 212 studies together with the literature search strategy are summarized in ref [30]. ${ }^{2}$ Of these, 31 studies had more than one observational, control or intervention group and four studies provided both concurrent and non-concurrent control groups. Hence, the number of groups does not equal the number of studies. ${ }^{3}$ Data are the median and inter-quartile range (IQR). ${ }^{4} \mathrm{~A}$ VAP incidence or effect size was not available for 27 studies. ${ }^{5}$ ICU mortality or effect size was not available for 35 studies.

Surprisingly, studies of applications of TAP appear to less effective among studies with non-concurrent controls. Indeed, the largest study of TAP to date, including 8665 mechanically ventilated patients among 13 European ICUs, failed to demonstrate any significant reductions in either ICU-acquired bacteremia or mortality at any timepoint, with or without adjustment for underlying patient disease severity [32].

The basis for this asymmetry between the results of studies with concurrent control patients versus the results of studies with non-concurrent control patients is puzzling. However, there may be parallels between the infection prevention experience using antibiotics in the ICU versus the experience with the use of vaccinations to induce protection against infection among populations in the broader community. In studies of vaccinations, it is important to separately estimate the possibly asymmetric effects of the vaccine intervention in extending the benefit to individual members of a population versus the effect obtained by the population as a whole from the herd protection if sufficient vaccination coverage is achieved by the vaccination program $[33,34]$. 'Cocooning' is given as a specific example of this herd protection within a population and how it may help us to understand the asymmetrical effects of antibiotic use in the ICU environment and the importance of study design to account for this. 


\section{Cocooning and Herd Effects}

Those becoming parents or grandparents are advised to be vaccinated against Pertussis. Vaccination of the adults in the household reduces the risk of acquiring Bordetella pertussis, the causative agent of whooping cough, for a vulnerable newborn in the first few months of life when their immune system is unresponsive to Pertussis vaccination.

This immunization of the parents to protect the newborn is cocooning, a specific example of herd protection, a concept generally pertinent to infection preventative interventions applied to populations. Herd protection symmetrically confers protection on vulnerable unprotected members within a population from infections in the shared microbiome.

To what extent herd protection might apply to infection preventative interventions applied in the ICU context remains unclear. Figure 1 illustrates how herd effects in the ICU might be conceived and how they could asymmetrically influence the apparent infection preventative 'effect' by indirect effects to non-recipients within an RCT.

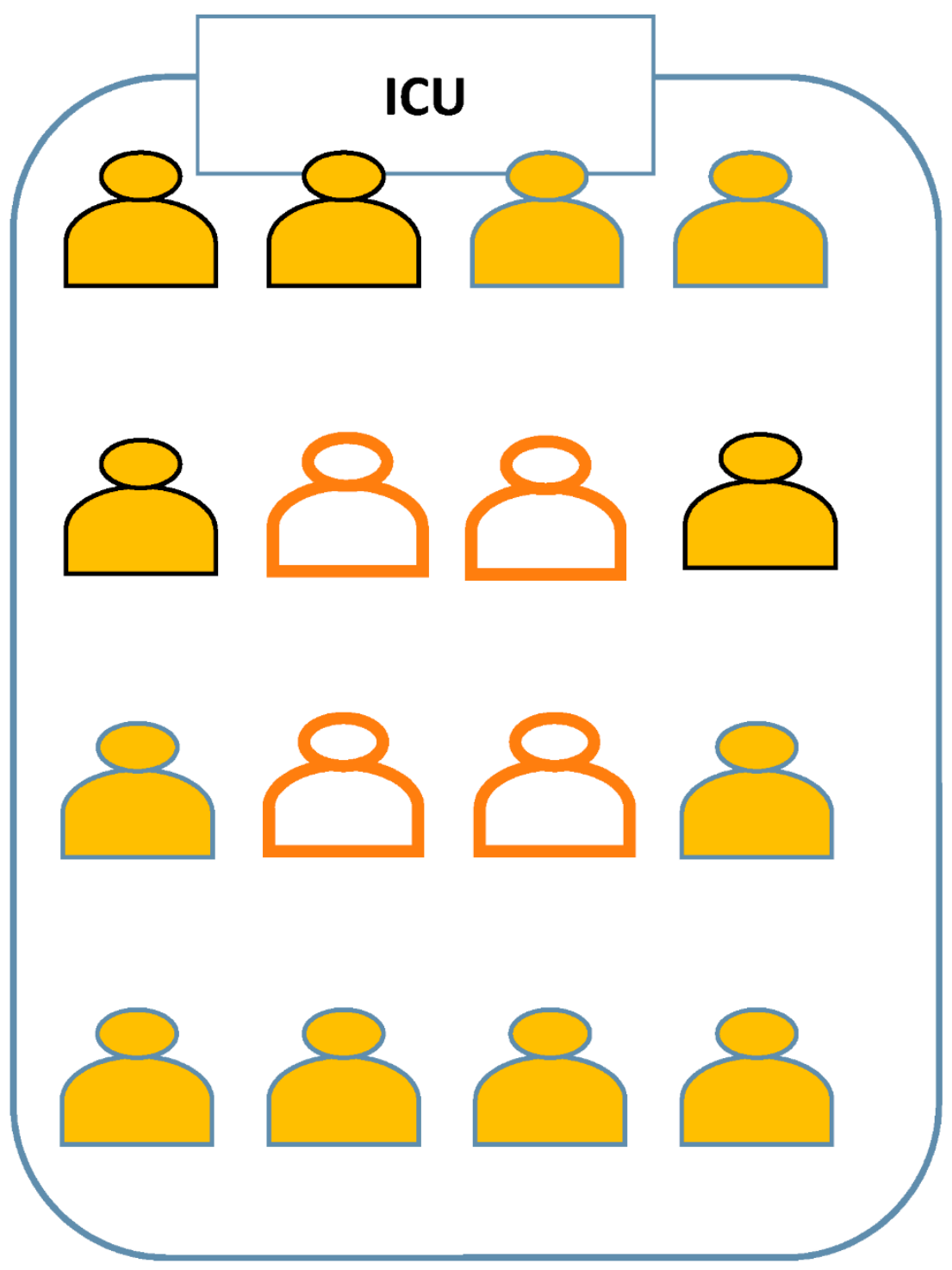

Figure 1. Herd protection (cocooning) within a population (e.g., patients within an ICU) provided to the concurrent non-recipient patients (open symbols) from a prevention intervention, such as a vaccination, given to those recipients randomized to receive the intervention (closed symbols). Are the direct effects for recipients and the indirect effects for non-recipients symmetrical or asymmetrical? 
Whilst herd protection resulting from vaccination programs delivered to populations is generally accepted and widely understood conceptually, its demonstration is not simple. Its measurement requires large purpose designed studies that are powered to demonstrate a lower than expected incidence of the specific infection of interest among the non-recipient minority within a population vaccination program. This requires large cluster randomized trials (CRTs) [33,34]. A demonstration of herd protection within a CRT of a typhoid vaccine program would generally require $>20,000$ residents among $>40$ neighborhoods to achieve sufficient statistical power. Half the neighborhoods would be randomized to typhoid vaccination versus control vaccination among the other neighborhoods. The incidence of typhoid among non-recipients of either vaccine, such as those ineligible or difficult to reach, would be the endpoint of interest in this type of study [35,36].

\section{Independence Assumption}

Any influence of a study intervention on concurrent control patients, such as would be expected to apply with a vaccine intervention by providing herd protection, is problematic for its evaluation. This could occur within the typical trial design with random allocation of intervention versus standard care to concurrently located patients. Likewise, in the evaluation of an intervention to prevent ICU-acquired infections, there are three reasons why the concept of herd effects should be a crucial consideration in their evaluation. First, the ICU context contributes to the risk of acquiring infection. Second, any evidence of herd protection would provide tremendous endorsement for an intervention. Third, any reduction in infection risk among concurrent patients resulting from herd protection from the infection preventative intervention within the ICU environment would be problematic within RCTs using concurrent control patients. Potentially, any reduction in infection risk among concurrent control group patients would bias the findings toward the null and obscure the detection of preventative effects. The first TAP study stated that " . . a reduction in the number of contagious patients by applying SDD in half of them, might reduce the acquisition, colonization and infection incidence in the not SDD treated control group" [37] (p. 186). Indeed, many subsequent TAP studies, including the largest and most recent study of TAP, by design, intentionally used non-concurrent controls to avoid the possible contamination of the control group by indirect effects spilling over from the intervention group [22].

If, on the other hand, the intervention was to increase the infection risk among concurrent patients through, for example, a change in the shared ICU microbiome, this, as herd peril, would bias the result of an RCT away from the null. Moreover, studying an intervention with any chance of herd peril would present unique ethical difficulties [38].

\section{Inference Threat}

The assumption of the independence of the outcomes between control and intervention groups is fundamental for causal inference of any intervention effects derived from an RCT. Testing the assumption of independence of outcomes for the control and intervention groups of an RCT of an intervention to prevent ICU-acquired infection is impossible within the confines of a single study. Given there are reasons to doubt the independence of the outcomes between the control and intervention groups, this independence would need to be tested, usually by reference to the incidence of the study endpoint of interest to an external incidence benchmark. Any inability to presume or verify the independence assumption would present a major threat to any inference of causality that might usually follow from observing significant effects within an RCT. The uncertainty regarding control group independence also applies to non-concurrent trials with cross-over, wherein control periods follow treatment periods, given there is risk of carryover contaminating control periods [39]. 


\section{The Natural Experiment}

Estimating herd effects in the ICU would seem problematic given the complexities described above. Moreover, to design and execute such a study would be conceptually challenging, logistically complex and potentially unethical. However, there is a natural experiment that might provide insights into herd effects within the ICU [40]. Could the studies within the VAP prevention evidence base be used as a natural experiment? The intervention of specific interest here is exposing the ICU microbiome and environment to patients receiving TAP. The study endpoint is any of several commonly reported outcomes such as VAP, bacteremia, candidemia or mortality within patients of ICUs not exposed to patients receiving TAP versus those groups exposed to patients receiving TAP and concurrently located in the ICU. Of note, the interest here is herd effects, which would be expected to be apparent at the level of the ICU population rather than at the level of the individual ICU patient. These ICU populations, as reported in the literature, can be conceived as having been assigned to different interventions somewhat analogous to the allocation by neighborhood of vaccinations programs in the typhoid herd immunity studies. Given TAP-based methods have the most apparent infection prevention effects, their potential to confer herd effects is of great interest. By contrast, other interventions, such as non-decontamination interventions, have minimal direct patient effects and would be expected to confer no herd effects. ICU populations with no study intervention could serve as observational groups and provide external benchmarks for whichever endpoint is of interest.

The setup of this natural experiment symmetrically 'flips' how these studies were originally conceived. In particular, the concurrent control groups within TAP studies are expected to be subject to the influence of herd effects resulting from the intervention. The other groups, be they non-concurrent control groups of TAP studies or control or even intervention groups of studies of interventions with little or no established prevention or herd effects, now collectively serve to provide several differently exposed 'control' groups of this natural experiment, all versus the external benchmarks derived from studies without an intervention. By comparing the event rates between the concurrent control groups within ICUs having patients receiving the study intervention to the event rates in the aggregate of other types of control groups from other studies, including studies of other interventions, provides the estimate of the herd effects.

The results of this symmetrical 'natural experiment' for a range of endpoints are reported in detail elsewhere [40-45]. The findings for VAP incidence and ICU mortality incidence derived from this 'natural experiment' based on an updated analysis of 212 RCT and other studies of ICU populations are presented in Figures $2-5$. The original data are accessible in [30].

Figures 2-5 display the VAP and ICU mortality endpoints for all group categories each versus respective literature benchmarks derived from the observational publications versus year of publication between the years 1985 to 2020. There has been no significant change in the incidence of either endpoint over the thirty-five-year period of these publications; each literature-derived benchmark is presented for comparison (green line). Of note, the incidence of each is higher in the concurrent control groups within RCTs of TAP (Figure 5, open red symbols, dashed lines) versus the externally-derived benchmark. For VAP incidence, this is eight percent and for ICU mortality this is five percent higher versus the benchmark. By contrast, the mean incidences for each of the following categories are each similar to the external benchmarks: non-concurrent control groups within TAP studies, control groups of studies of non-decontamination interventions and control groups of studies of anti-septic interventions. Surprisingly, for all endpoints except VAP, the mean incidences of each within TAP intervention groups are similar to the benchmark, not lower. Of note, in each case, these findings are consistent with TAP appearing to have a 'preventive effect' within RCTs using concurrent controls [31], but not within CRTs using non-concurrent controls [32]. 
One further surprising finding from this 'natural experiment' concerns the event rates within the TAP intervention groups for the incidences of infections with specific bacteria. The constituents of TAP are polymyxin, tobramycin and amphotericin. These antibiotics and amphotericin are active against Pseudomonas, Acinetobacter and Candida. The incidences of bacteremia with Pseudomonas [29,43], Acinetobacter [29] and Candida [4,42] among TAP intervention groups receiving TAP regimens containing polymyxin, tobramycin and amphotericin are similar to the benchmark. This is profoundly paradoxical and asymmetrical. Likewise, the incidences of VAP and bacteremia with Staphylococcus aureus versus respective Staph aureus benchmarks are profoundly paradoxical [44,45]. Of note, the cross infection underlying these differences would not be apparent within the individual studies examined in isolation given their limited sizes [46].

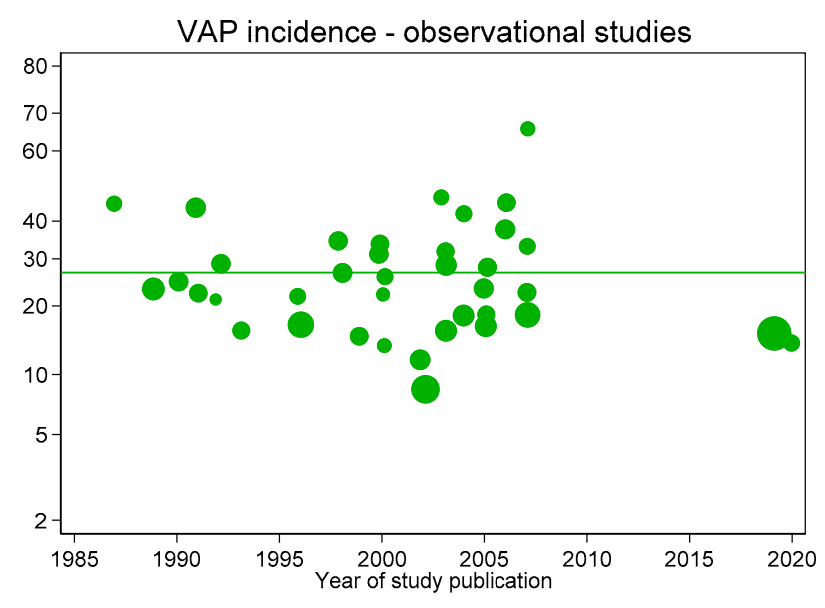

(a)

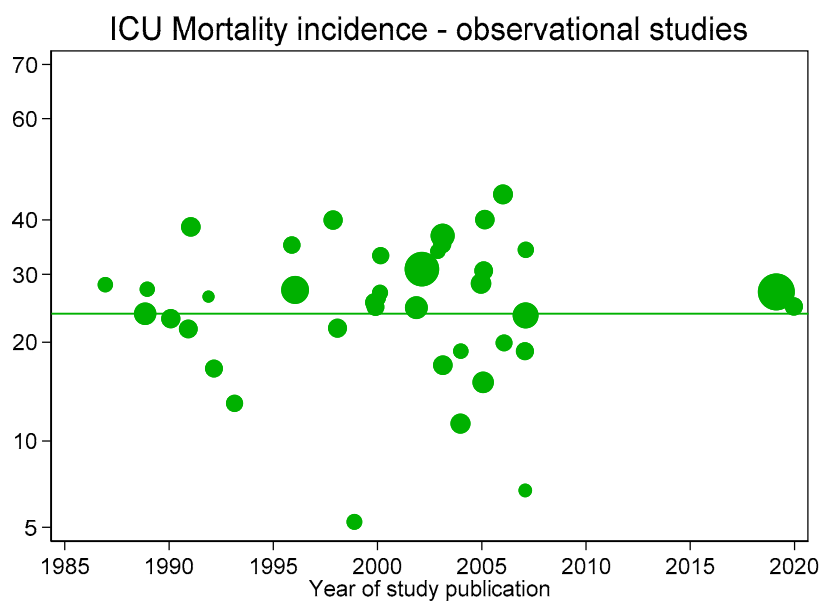

(b)

Figure 2. VAP (a) and ICU mortality (b) incidences per 100 patients as reported in groups from studies without intervention (observational studies; green symbols) versus year of publication. In each figure, the mean (green line) is shown as a benchmark. Note: Logit scale on y axis, data from [30].

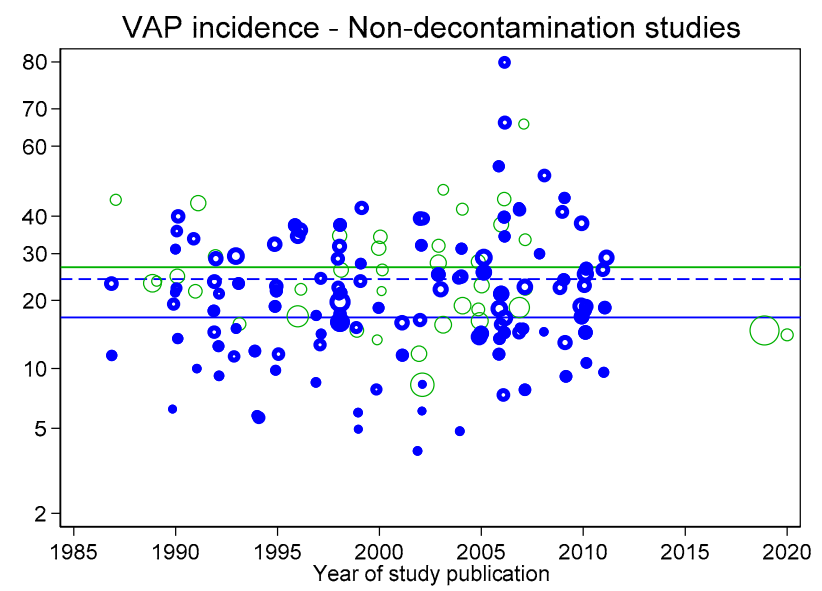

(a)

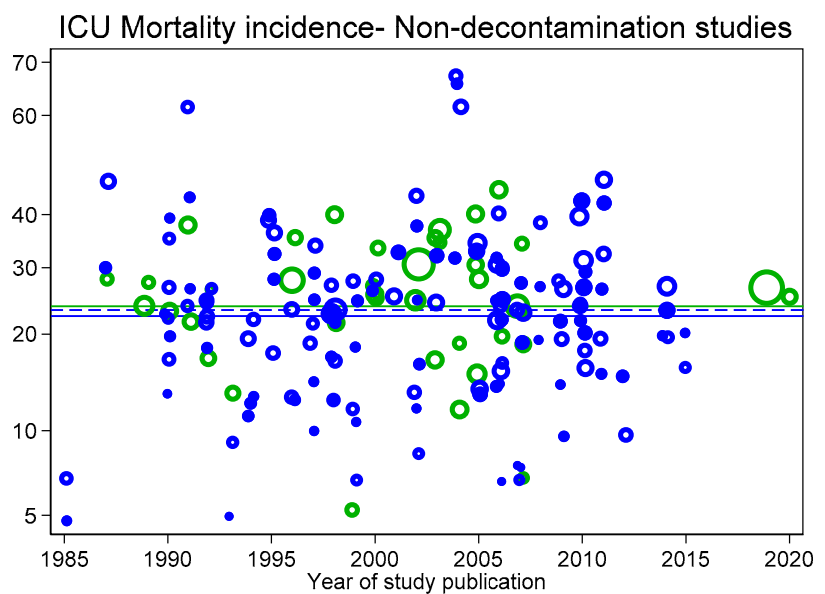

(b)

Figure 3. VAP (a) and ICU mortality (b) incidences for concurrent control (open blue symbols and mean; dashed blue line) and intervention (closed blue symbols and mean; solid blue line) from non-decontamination intervention studies versus year of publication. In each figure, the incidences per 100 patients as reported in groups from studies without intervention (observational studies; open green symbols) and the associated mean (green line from Figure 2) are shown as benchmarks. Not: Logit scale on y axis, data from [30]. 


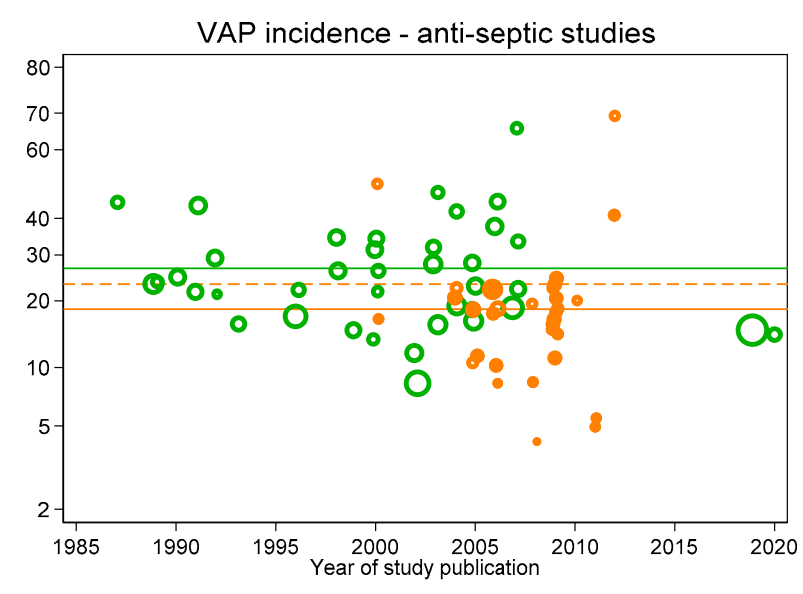

(a)

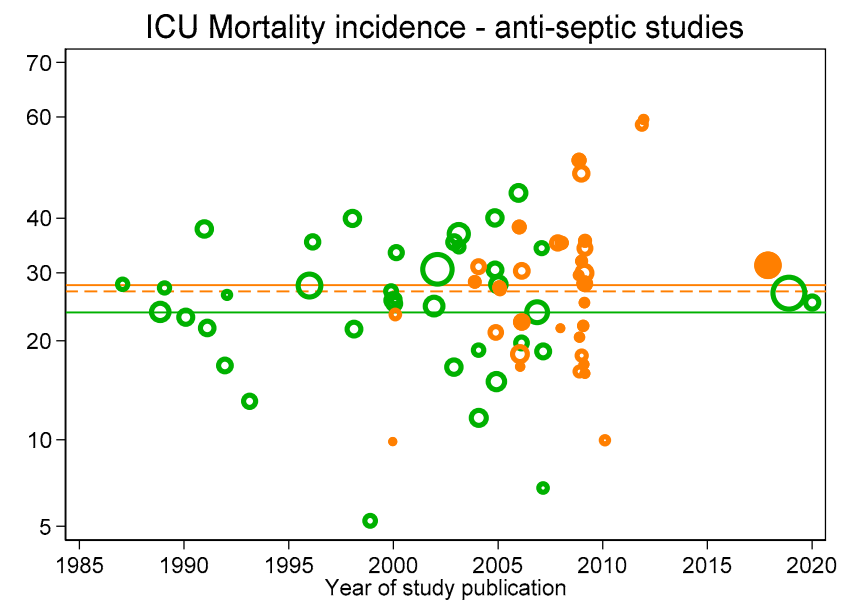

(b)

Figure 4. VAP (a) and ICU mortality (b) incidences for concurrent control (open orange symbols and mean; dashed orange line) and intervention (closed orange symbols and mean; solid orange line) from antiseptic intervention studies versus year of publication. In each figure, the incidences per 100 patients as reported in groups from studies without intervention (observational studies; open green symbols) and the associated mean (green line from Figure 2) are shown as benchmarks. Note: Logit scale on y axis, data from [30].

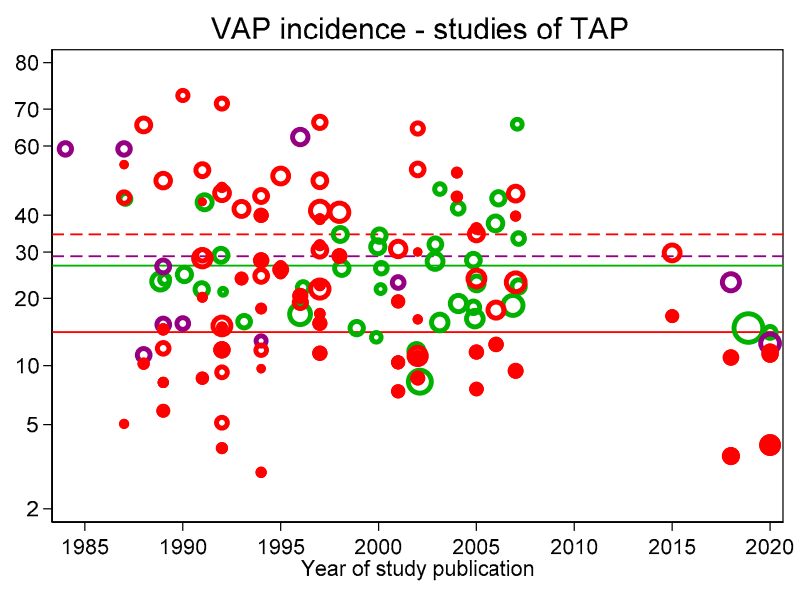

(a)
ICU mortality incidence - studies of TAP

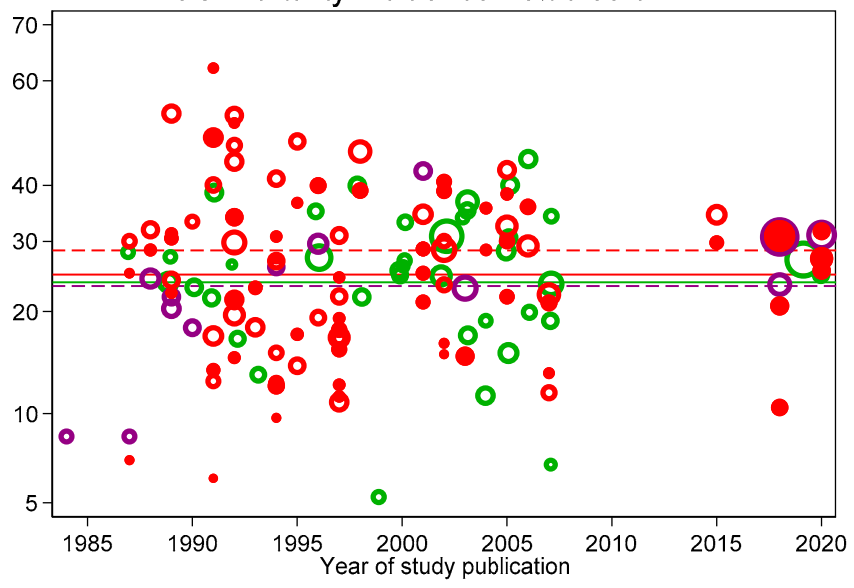

(b)

Figure 5. VAP (a) and ICU mortality (b) incidences for concurrent control (open red symbols and mean; dashed red line), non-concurrent control (open purple symbols and mean; dashed purple line) and intervention (closed red symbols and mean; solid red line) from topical antibiotic prophylaxis (TAP) intervention studies versus year of publication. In each figure, the incidences per 100 patients as reported in groups from studies without intervention (observational studies; open green symbols) and the associated benchmark mean (green line from Figure 2) are shown. Note: Logit scale on y axis, data from [30].

\section{Conclusions}

There is an unsubstantiated presumption that the effect of prophylactic antibiotics on ICU patients at the patient level and the population level would be symmetrical. This review considers the evidence from a wide range of studies to test this presumption using an approach that symmetrically 'flips' the control and intervention groups.

Considerable uncertainty remains as to what effects, if any, TAP might provide toward preventing ICU acquired infections. The non-independence assumption requirement for 
the RCTs described above remains unverified and is likely untenable, as postulated in the first TAP study [37].

There is no evidence for protective cocooning effects from using TAP to prevent ICU acquired infections. Indeed, the high incidence of multiple endpoints, including VAP and ICU mortality, among concurrent control groups of TAP-RCTs raises concern that the herd effects of TAP are harmful [39]. Moreover, these herd effects, as herd peril, could underlie the apparent preventive 'effect' of TAP as observed within TAP-RCTs.

Using antibiotics as an infection prevention intervention within the ICU environment may result in profoundly asymmetrical effects at the level of the individual patient versus the level of the population.

Author Contributions: As sole author, J.C.H. produced the design of the study, performed the statistical analysis and wrote the manuscript. J.C.H. read and approved the final manuscript and is the guarantor of the paper. The author has read and agreed to the published version of the manuscript.

Funding: This research has been supported by the Australian Government Department of Health and Ageing through the Rural Clinical Training and Support (RCTS) program.

Institutional Review Board Statement: Not applicable.

Informed Consent Statement: Not applicable.

Data Availability Statement: Data for Figures $2-5$ is available within reference [30] an open-access article distributed under the terms of the Creative Commons Attribution-Non Commercial-No Derivatives License 4.0 (CCBY-NC-ND).

Acknowledgments: Not applicable.

Conflicts of Interest: The author declares that he has no competing interests. The funders had no role in the design of the study; in the collection, analyses, or interpretation of data; in the writing of the manuscript, or in the decision to publish the results.

\section{References}

1. Lambert, M.-L.; Suetens, C.; Savey, A.; Palomar, M.; Hiesmayr, M.; Morales, I.; Agodi, A.; Frank, U.; Mertens, K.; Schumacher, M.; et al. Clinical outcomes of health-care-associated infections and antimicrobial resistance in patients admitted to European intensive-care units: A cohort study. Lancet Infect. Dis. 2011, 11, 30-38. [CrossRef]

2. Hurley, J.C. Profound effect of study design factors on ventilator-associated pneumonia incidence of prevention studies: Benchmarking the literature experience. J. Antimicrob. Chemother. 2008, 61, 1154-1161. [CrossRef] [PubMed]

3. Hurley, J.C. Topical antibiotics as a major contextual hazard toward bacteremia within selective digestive decontamination studies: A meta-analysis. BMC Infect. Dis. 2014, 14, 714. [CrossRef] [PubMed]

4. Hurley, J.C. ICU-acquired candidemia within selective digestive decontamination studies: A meta-analysis. Intensive Care Med. 2015, 41, 1877-1885. [CrossRef] [PubMed]

5. Roquilly, A.; Marret, E.; Abraham, E.; Asehnoune, K. Pneumonia Prevention to Decrease Mortality in Intensive Care Unit: A Systematic Review and Meta-analysis. Clin. Infect. Dis. 2014, 60, 64-75. [CrossRef]

6. Kollef, M.H.; Micek, S.T. Rational use of antibiotics in the ICU: Balancing stewardship and clinical outcomes. JAMA 2014, 312, 1403-1404. [CrossRef]

7. Daneman, N.; Sarwar, S.; Fowler, R.; Cuthbertson, B.H.; SuDDICU Canadian Study Group. Effect of selective decontamination on antimicrobial resistance in intensive care units: A systematic review and meta-analysis. Lancet Infect. Dis. 2013, 13, 328-341. [CrossRef]

8. Plantinga, N.; de Smet, A.; Oostdijk, E.; de Jonge, E.; Camus, C.; Krueger, W.; Bergmans, D.; Reitsma, J.; Bonten, M. Selective digestive and oropharyngeal decontamination in medical and surgical ICU patients: Individual patient data meta-analysis. Clin. Microbiol. Infect. 2018, 24, 505-513. [CrossRef] [PubMed]

9. Zhao, D.; Wu, Y.; Song, J.; Gao, F.; Gao, X.; Lu, Y.; Hou, K. Selective oropharyngeal decontamination versus selective digestive decontamination in critically ill patients: A meta-analysis of randomized controlled trials. Drug Des. Dev. Ther. 2015, 9, 3617-3624. [CrossRef]

10. Liberati, A.; D'Amico, R.; Pifferi, S.; Torri, V.; Brazzi, L.; Parmelli, E. Antibiotic prophylaxis to reduce respiratory tract infections and mortality in adults receiving intensive care (Review). Cochrane Database Syst. Rev. 2009, 4, CD000022.

11. Pileggi, C.; Bianco, A.; Flotta, D.; Nobile, C.G.; Pavia, M. Prevention of ventilator-associated pneumonia, mortality and all intensive care unit acquired infections by topically applied antimicrobial or antiseptic agents: A meta-analysis of randomized controlled trials in intensive care units. Crit. Care 2011, 15, R155. [CrossRef] 
12. Silvestri, L.; Van Saene, H.K.F.; Casarin, A.; Berlot, G.; Gullo, A. Impact of Selective Decontamination of the Digestive Tract on Carriage and Infection Due to Gram-Negative and Gram-Positive Bacteria: A Systematic Review of Randomised Controlled Trials. Anaesth. Intensive Care 2008, 36, 324-338. [CrossRef] [PubMed]

13. Hurley, J. Prophylaxis with enteral antibiotics in ventilated patients: Selective decontamination or selective cross-infection? Antimicrob. Agents Chemother. 1995, 39, 941-947. [CrossRef] [PubMed]

14. Silvestri, L.; Van Saene, H.; Milanese, M.; Gregori, D.; Gullo, A. Selective decontamination of the digestive tract reduces bacterial bloodstream infection and mortality in critically ill patients. Systematic review of randomized, controlled trials. J. Hosp. Infect. 2007, 65, 187-203. [CrossRef] [PubMed]

15. Silvestri, L.; Weir, W.I.; Gregori, D.; Taylor, N.; Zandstra, D.F.; Van Saene, J.J.; Van Saene, H.K. Impact of Oral Chlorhexidine on Bloodstream Infection in Critically Ill Patients: Systematic Review and Meta-Analysis of Randomized Controlled Trials. J. Cardiothorac. Vasc. Anesth. 2017, 31, 2236-2244. [CrossRef]

16. Klompas, M.; Speck, K.; Howell, M.D.; Greene, L.R.; Berenholtz, S.M. Reappraisal of routine oral care with chlorhexidine gluconate for patients receiving mechanical ventilation: Systematic review and meta-analysis. JAMA Intern. Med. 2014, 174, 751-761. [CrossRef] [PubMed]

17. Alhazzani, W.; Smith, O.; Muscedere, J.; Medd, J.; Cook, D. Toothbrushing for Critically Ill Mechanically Ventilated Patients: A Systematic Review and Meta-Analysis of Randomized Trials Evaluating Ventilator-Associated Pneumonia. Crit. Care Med. 2013, 41, 646-655. [CrossRef]

18. Han, J.; Liu, Y. Effect of ventilator circuit changes on ventilator-associated pneumonia: A systematic review and meta-analysis. Respir. Care 2010, 55, 467-474.

19. Subirana, M.; Solà, I.; Garcia, J.; Laffaire, E.; Benito, S. Closed tracheal suctions systems versus open tracheal systems for mechanically ventilated adult patients. Cochrane Database Syst. Rev. 2003, 4, 004581. [CrossRef]

20. Siempos, I.I.; Vardakas, K.Z.; Kopterides, P.; Falagas, M.E. Impact of passive humidification on clinical outcomes of mechanically ventilated patients: A meta-analysis of randomized controlled trials. Crit. Care Med. 2007, 35, 2843-2851.

21. Muscedere, J.; Rewa, O.; McKechnie, K.; Jiang, X.; LaPorta, D.; Heyland, D.K. Subglottic secretion drainage for the prevention of ventilator-associated pneumonia: A systematic review and meta-analysis. Crit. Care Med. 2011, 39, 1985-1991. [CrossRef] [PubMed]

22. Delaney, A.; Gray, H.; Laupland, K.B.; Zuege, D.J. Kinetic bed therapy to prevent nosocomial pneumonia in mechanically ventilated patients: A systematic review and meta-analysis. Crit. Care 2006, 10, R70. [CrossRef] [PubMed]

23. Sud, S.; Friedrich, J.O.; Taccone, P.; Polli, F.; Adhikari, N.K.J.; Latini, R.; Pesenti, A.; Guérin, C.; Mancebo, J.; Curley, M.A.Q.; et al. Prone ventilation reduces mortality in patients with acute respiratory failure and severe hypoxemia: Systematic review and meta-analysis. Intensive Care Med. 2010, 36, 585-599. [CrossRef] [PubMed]

24. Siempos, I.I.; Vardakas, K.Z.; Falagas, M.E. Closed tracheal suction systems for prevention of ventilator-associated pneumonia. Brit. J. Anaesth. 2008, 100, 299-306. [CrossRef] [PubMed]

25. Messori, A.; Trippoli, S.; Vaiani, M.; Gorini, M.; Corrado, A. Bleeding and pneumonia in intensive care patients given ranitidine and sucralfate for prevention of stress ulcer: Meta-analysis of randomised controlled trials. BMJ 2000, 321, 1103-1106. [CrossRef]

26. Huang, J.; Cao, Y.; Liao, C.; Wu, L.; Gao, F. Effect of histamine-2-receptor antagonists versus sucralfate on stress ulcer prophylaxis in mechanically ventilated patients: A meta-analysis of 10 randomized controlled trials. Crit. Care 2010, 14, R194. [CrossRef]

27. Alhazzani, W.; Almasoud, A.; Jaeschke, R.; Lo, B.W.Y.; Sindi, A.; Altayyar, S.; Fox-Robichaud, A. Small bowel feeding and risk of pneumonia in adult critically ill patients: A systematic review and meta-analysis of randomized trials. Crit. Care 2013, 17, R127. [CrossRef]

28. Silvestri, L.; Miguel, A.; van Saene, H.K. Selective decontamination of the digestive tract: The mechanism of action is control of gut overgrowth. Intensive Care Med. 2012, 38, 1738-1750. [CrossRef]

29. Hurley, J.C. Structural equation modeling the "control of gut overgrowth" in the prevention of ICU-acquired Gram-negative infection. Crit. Care 2020, 24, 1-12. [CrossRef]

30. Hurley, J.C. Discrepancies in Control Group Mortality Rates within Studies Assessing Topical Antibiotic Strategies to Prevent Ventilator-Associated Pneumonia: An Umbrella Review. Crit. Care Explor. 2020, 2, e0076. [CrossRef] [PubMed]

31. Minozzi, S.; Pifferi, S.; Brazzi, L.; Pecoraro, V.; Montrucchio, G.; D’Amico, R. Topical antibiotic prophylaxis to reduce respiratory tract infections and mortality in adults receiving mechanical ventilation. Cochrane Database Syst. Rev. 2021, 1, CD000022. [CrossRef]

32. Wittekamp, B.H.; Plantinga, N.L.; Cooper, B.S.; Lopez-Contreras, J.; Coll, P.; Mancebo, J.; Wise, M.P.; Morgan, M.P.; Depuydt, P.; Boelens, J.; et al. Decontamination strategies and bloodstream infections with antibiotic-resistant microorganisms in ventilated patients: A randomized clinical trial. JAMA 2018, 320, 2087-2098. [CrossRef] [PubMed]

33. Benn, C.S.; Fisker, A.B.; Rieckmann, A.; Sørup, S.; Aaby, P. Vaccinology: Time to change the paradigm? Lancet Infect. Dis. 2020, 20, e274-e283. [CrossRef]

34. de Cellès, M.D.; Riolo, M.A.; Magpantay, F.M.; Rohani, P.; King, A.A. Epidemiological evidence for herd immunity induced by acel-lular pertussis vaccines. Proc. Natl. Acad. Sci. USA 2014, 111, E716-E717. [CrossRef] [PubMed]

35. Hurley, J.C. How the Cluster-randomized Trial “Works". Clin. Infect. Dis. 2020, 70, 341-346. [CrossRef]

36. Clemens, J.; Shin, S.; Ali, M. New approaches to the assessment of vaccine herd protection in clinical trials. Lancet Infect. Dis. 2011, 11, 482-487. [CrossRef] 
37. Stoutenbeek, C.P.; Van Saene, H.K.F.; Miranda, D.R.; Zandstra, D.F. The effect of selective decontamination of the digestive tract on colonisation and infection rate in multiple trauma patients. Intensive Care Med. 1984, 10, 185-192. [CrossRef]

38. Hurley, J.C. Ventilator-associated pneumonia prevention methods using topical antibiotics: Herd protection or herd peril? Chest 2014, 146, 890-898. [CrossRef]

39. Hurley, J.C. Pro: Selective Digestive Decontamination Is Neither Safe Nor Efficacious for Critically Ill Patients. Crit. Care Med. 2019, 48, 732-735. [CrossRef]

40. Hurley, J.C. Incidence of coagulase-negative staphylococcal bacteremia among ICU patients: Decontamination studies as a natural experiment. Eur. J. Clin. Microbiol. Infect. Dis. 2019, 39, 657-664. [CrossRef]

41. Hurley, J.C. Studies of selective digestive decontamination as a natural experiment to evaluate topical antibiotic prophylaxis and cephalosporin use as population-level risk factors for enterococcal bacteraemia among ICU patients. J. Antimicrob. Chemother. 2019, 74, 3087-3094. [CrossRef] [PubMed]

42. Hurley, J.C. Impact of selective digestive decontamination on respiratory tract Candida among patients with suspected ventilatorassociated pneumonia. A meta-analysis. Eur. J. Clin. Microbiol. Infect. Dis. 2016, 35, 1121-1135. [CrossRef] [PubMed]

43. Hurley, J.C. Unusually High Incidences of Pseudomonas Bacteremias within Topical Polymyxin-Based Decolonization Studies of Mechanically Ventilated Patients: Benchmarking the Literature. Open Forum Infect. Dis. 2018, 5, ofy256. [CrossRef]

44. Hurley, J.C. The Perfidious Effect of Topical Placebo: Calibration of Staphylococcus aureus Ventilator-Associated Pneumonia Incidence within Selective Digestive Decontamination Studies versus the Broader Evidence Base. Antimicrob. Agents Chemother. 2013, 57, 4524-4531. [CrossRef]

45. Hurley, J.C. Unusually High Incidences of Staphylococcus aureus Infection within Studies of Ventilator Associated Pneumonia Prevention Using Topical Antibiotics: Benchmarking the Evidence Base. Microorganism 2018, 6, 2. [CrossRef] [PubMed]

46. Hurley, J.C. Inapparent Outbreaks of Ventilator-Associated Pneumonia: An Ecologic Analysis of Prevention and Cohort Studies. Infect. Control. Hosp. Epidemiol. 2005, 26, 374-390. [CrossRef] 